\title{
MODULAÇÕES TEOPOÉTICAS DA HISTÓRIA: ÉPICA E PROFECIA EM CORSINO FORTES
}

THEOPOETIC MODULATIONS OF HISTORY: EPIC AND PROPHETIC DISCOURSES IN CORSINO FORTES

\section{Gonçalo Cordeiro}

Universidade de Macau

Macau - China

\section{Resumo}

Este artigo propóe uma leitura da obra poética de Corsino Fortes, $A$ Cabeça Calva de Deus, sob a óptica de uma visão literariamente constituída sobre o passado e o devir de Cabo Verde. Será meu propósito explorar o modo como a discursivização épica desta poesia investe numa poética marcadamente bíblica na sua figuração, tematização e injunção (numa paleta que se estende do profético ao escatológico). Por meio da associação elemental entre o mítico e o natural, o argumento explora a forma como esta poesia elege o profético (frequentemente associado ao anúncio do futuro) como possibilidade de reflexão sobre a história (não necessariamente já passada). Será objecto de auscultação a esfera de sacralidade que o texto para si reclama, colocando-se sob o signo de um imaginário bíblico ritualizante, que procede à ressemantização do discurso literário sobre a nação.

Palavras-chave: Poesia épica, profecia, Corsino

\section{Abstract}

This article proposes a reading of Corsino Fortes' A Cabeça Calva de Deus in the light of a literarily-constructed perspective on the past and the future of Cape Verde. It is my claim that his poetry invests in forms of Biblical figures, themes and discursive injunctions, in a range which goes from the prophetic to the apocalyptic, producing a heteroclite and omnivorous poetic mythology. By bringing together mythical and natural elements, Corsino seems to explore the potentialities of the prophetic mode (usually associated with the future) as

\section{Résumé}

Cet article propose une lecture de la poésie de Corsino Fortes, A Cabeça calva de Deus, dans la perspective d'une vision littérairement formée du passé et du devenir du Cap-Vert. Mon objectif sera d'interroger comment cette poésie épique investit sur des formes bibliques, en ce qui concerne sa figuration, thématisation et injonction (une palette s'étendant de la scatologie à la prophétie). Grâce à l'association élémentaire entre le mythique et le naturel, l'argument explore comment cette poésie élit le prophétique (souvent associée à l'avenir) comme 
a possibility of reflecting upon history. We will then consider how the sphere of sacredness created in the text calls for an understanding of the power of the Biblical imaginary as a literary source for the resemantization of the discourse about the nation.

Keywords: Epic poetry, prophecy, Corsino. une moyen de réfléchir sur l'histoire (pas nécessairement déjà passée). Mon propos se recentre sur une idée de sacré textuel qui retrouve dans l'imaginaire biblique une source littéraire pour la resémantization du discours sur la nation.

Mots-clés: Poésie épique, prophétie, Corsino.

A aliança clássica entre poesia e profecia não é um epifenómeno da história literária; ela molda desde tempos imemoriais uma relação discursiva que alia a palavra à ordem do sagrado e à sua percepção religiosa. A teoria da inspiração poética, como a consagrada no Ín, retoma essa associação primordial entre a poiesis e a possessão, que, se por um lado, faz do poeta um porta-voz do divino, por outro lado, viria a derivar na expulsáo do poeta do espaço da pólis, na linha platónica de uma crítica religiosa da literatura (RUBINSTEIN, 2007). A acção do poeta não está, pois, menos ligada ao mundo dos homens do que ao mundo dos deuses, contiguando-os por meio de uma mesma palavra que se declina de modos vários, em refracção poética. Dos modos de declinação de uma tal palavra poderá dizer-se ainda que estes não se encontram arredados de uma reflexão sobre a natureza da história nem dos discursos que ela suscita, como me parece ser o caso da poesia de Corsino Fortes. ${ }^{1}$

Em $A$ Cabeça calva de Deus (2001), súmula poética da produção literária de Corsino, encontramos um edifício macroestrutural que se estatui em torno de três naves arquitectónicas, a saber, Pão \&o fonema (1974), Árvore ơ tambor (1986), Pedras de sol e Substância (2001). Os relevantes contributos críticos de Christina Ramalho e Ana Mafalda Leite, para destacar apenas alguns, têm assinalado o modo como este título reúne numa unidade tríptica um projecto literário que compagina uma "épica cabo-verdiana e universal" (RAMALHO, 2012: 203) e uma “épica fundacional” (LEITE, 1996: 267). Esta poesia obedece, então, como bem viu Pires Laranjeira, a um projecto de concatenação criativa, levado a cabo ao longo de várias décadas, que se presta à “celebração poética da condição cabo-verdiana” (LARANJEIRA, 1995: 240).

No entanto, se a matriz épica parece oferecer um modelo categorial adequado para concepção dessa poesia, e muitos são os argumentos relevantes

\footnotetext{
${ }^{1}$ Corsino Fortes (1933-2015), poeta cabo-verdiano, foi fundador do PAIGC (Partido Africano para a Independência da Guiné-Bissau e Cabo Verde), tendo, também, frequentado a Casa dos Estudantes do Império, em Lisboa. Foi Ministro e Secretário de Estado, bem como embaixador em Portugal. Para além da trilogia A Cabeça calva de Deus, publicou Sinos de silêncio (Cançöes e Haikais) em 2015.
} 
que favorecem tais leituras, aquela por si só não parece descrever a totalidade literária do alcance semântico, simbólico e mítico dela. O epos heróico que caracteriza as referências matriciais do género no ocidente ${ }^{2}$ implica a existência de um herói e a condução de uma acção heróica, em torno da qual se estabelece a narrativa. A acção bélica, do confronto guerreiro, a errância ulisseica e argonáutica, a aventura amorosa e a gesta cavaleiresca ${ }^{3}$ inscrevem-se, na verdade, apenas de forma oblíqua e não propriamente narrativizada em $A$ Cabeça Calva de Deus, também na medida em que tais referências, embora reconhecíveis, são ali actualizadas por meio de uma transmutação poética que as recoloca no quadro das "limitaçóes geoclimáticas e telúricas" (LEITE, 2001: 293) do universo cabo-verdiano.

Em que sentido, então, se pode dizer épica a poesia de Corsino? Convém rememorar a plasticidade de que se reveste tal conceito na teorização literária. É sabido como textos basilares do cânone ocidental, da Comédia de Dante ao Paraíso Perdido de Milton, sem obedecerem estritamente aos códigos da categoria, foram também designados de épicos, por motivos vários: pela magnificência do seu projecto literário, pela grandiloquência do estilo, pela convocação dialéctica de matrizes culturais, de distinta índole literária, filosófica e histórica, pela refundaçáo poiética do nosso mundo no engendramento poético de mundos literários outros - por tudo isso certamente, mas náo menos pelo modo como tais obras transcenderam as tipologias clássicas de catalogação genológica, problematizando-as por meio de um traço essencial que lhes assiste: o seu polimorfismo discursivo. A este respeito, Hélio Alves ${ }^{4}$ destaca o seguinte como traço próprio do modo épico: "a épica confundese de tal maneira com as origens literárias da humanidade e é de tal modo consensualmente tratada como totalizante e híbrida, por excelência a soma de todos os discursos, que parece esvaziar-se das características eventualmente próprias que possa possuir" (2010).

Há, então, que distinguir entre o épico enquanto género, de ascendência estritamente homérica e vergiliana, e o épico enquanto modo, naturalmente trans-histórico e de feição universalizante, capaz de declinar-se em diferentes sub-géneros. Foi no quadro de uma modalização do épico que o mestre da filologia românica Ernst Curtius procedeu à subcategorização do modo em European Literature and Latin Middle Ages (1945), cunhando o género

\footnotetext{
${ }^{2}$ Podemos pensar, sem pretensão de exaustividade, numa paleta de referências que se estende desde a Epopeia de Gilgamesh, à epopeia da criação babilónica do Enuma Elish ("quando no alto"), às referências homéricas de A Iliada e de $A$ Odisseia, passando por $A$ Eneida de Vergílio e pelo seu decalque modelar em Os Lusiadas de Camóes.

${ }^{3}$ Ocorre-me sobretudo o modelo de Ariosto, com Orlando Furioso, e de Tasso, com Jerusalém libertada.

${ }^{4}$ Refira-se o seu trabalho de referência no estudo da epopeia quinhentista (de Camôes e Jerónimo CorteReal), O Sistema da epopeia quinhentista (1999, Universidade de Évora).
} 
da épica bíblica ou cristã e balizando-o na alta idade média5; sendo ainda ao lastro dessa tradição que o comparatista canadiano Northrop Frye, na sua obra monumental Anatomy of Criticism (2000: 315), faz remontar a coexistência da narrativa cristã e do mito clássico no épico cristão. É também a esta tradição que o filósofo William Franke recorre em Poetry and Apocalipse (2009) para recuperar o traço essencial que liga poesia e profecia, resgatando do esquecimento filológico esse género particular do épico cristáo, que se distingue pela sua particular forma de enciclopedismo literário, em que coincidem as matrizes clássica e bíblica. ${ }^{6}$

Se aqui convoco tais aspectos é porque me parece que eles farão sentido quando se trata de equacionar a propriedade do épico ${ }^{7}$ na obra de Corsino Fortes, em torno do qual parece ter-se estabelecido algum consenso crítico. Ora, o que neste ensaio se pretende é precisamente modalizar aquilo que na designação de épico não esgota a iridescência significativa dessa poesia, deixando espaço para aquilo que aqui proponho como modulação teopoética. Seria esta uma formulação possível para o acolhimento argumentativo ao lastro da profecia bíblica que se encontra colhido nessa obra, não necessariamente como derivação de um maravilhoso de ascendência épica, mas como componente de uma tradição bíblica que a literatura no ocidente viria a cristalizar de modos distintos (nomeadamente sob a formulação de épico cristão).

É evidente que o paradigma genológico do épico está, de facto, insuflado na génese da obra de Corsino Fortes, que ostensivamente procura a correspondência formal com o modelo da épica, organizando em cantos o que, de outra forma, seriam apenas capítulos e fazendo-os anteceder de "proposição". Em termos de narração do evento heróico na trilogia de Corsino, esta é difusa e dificilmente assinalável em termos objectivos, pois que está codificada num espectro alegórico e universalizante, que procura fazer coincidir a conquista da independência política da nação com o renascimento fundacional de uma nova pátria. Em meio ao coro da tragédia insular da seca e da fome, o poema conta a odisseia de um povo, elegendo o "povo cabo-verdiano como

\footnotetext{
${ }^{5}$ Sobre as especificidades da literatura épica cristã e sua contextualização medieval, remeto para o artigo de Cuervo (2011).

${ }^{6}$ Essa coincidência assume uma dicotomia proteica que se desdobra em pares como destruiçăo e cativeiro (Tróia e Babilónia), exílio e diáspora (Ítaca e a terra prometida), construção e fundaçăo de nova cidade (Roma e Nova Jerusalém). Neste género, se correspondem ainda os sentidos ambivalentes que se interpenetram a partir de dois universos referenciais distintos, como observou Eric Auerbach no seu ensaio seminal intitulado "A Cicatriz de Ulisses", com que abre Mimesis. Representaçôes da realidade na literatura ocidental (1946).

${ }^{7}$ Christina Ramalho sumariza da seguinte forma os elementos constitutivos de uma estética da epopeia: "dupla instância de enunciação - eu lírico/narrador -, presença dos planos histórico, maravilhoso e literário, heroísmo épico, deslocamento espacial ou simbólico, presença de dedicatória, proposição, invocação, divisão em cantos e identificação de uma matéria-épica: todos esses aspectos norteiam o reconhecimento do caráter épico de um poema longo" (2013: 373). Veja-se ainda, sobre o mesmo assunto, a obra de Ana Mafalda Leite (1996: 11-37).
} 
grande entidade predicática”, na designação de Pires Laranjeira (1995: 232), ou seja, o herói do poema, que ali surge refractado numa galeria de figuras como as mulheres da terra, as crianças da rua, os intelectuais e activistas políticos, os trabalhadores da terra e do mar - onde o texto vai buscar muita da sua coloração neorrealista. A matéria épica do poema pode dizer-se, então, a formação mítico-histórica da nação cabo-verdiana, pelas múltiplas e omnipresentes referências à fragmentação do território, ao seu clima e geografia, à história colonial e à mestiçagem do povo, como de resto assinala Christina Ramalho (2012: 206).

A formulação escolhida para o título do livro, A Cabeça calva de Deus, retoma um verso do segundo elemento do tríptico, Arvore \& tambor, e adopta como seu emblema fundamental uma divindade sem cabelo, ou de cabeça calva, sugerindo a alvura de umas câs inexistentes, quais as da velhice de um Padre eterno. Esse Deus envelhecido e silente observa, do alto da sua cabeça calva, o movimento da história, o de um passado e de um futuro confluindo para o presente, numa dinâmica que se repercute autorreflexivamente no momento da escrita e da leitura do livro de Corsino. Um tal efeito de coincidência de dois tempos, afim do discurso de natureza profética, muito se deve à retórica exclamativa e deíctica de raiz invocatória (o aqui e o agora que permanentemente convocam o leitor), num processo de efeitos metaliterários que procedem à religação do tempo da leitura ao tempo kairológico, o de um presente da acção e do verbo, afinal o tempo da eternidade de Deus, infundido no kronos da temporalidade humana.

É, por isso, tanto mais significativo que o título de Corsino não recorra ao nome de um herói épico (um Ulisses, um Eneias, um Orlando, os filhos de Luso), mas constitua uma referência à entidade transcendente que ali surge apresentada por sinédoque, topicalizada na medida da sua implicação na lei do tempo e, como tal, não imune à calvície nem ao efeito do transcorrer do tempo histórico. Essa cabeça divina, por sua vez, pode surgir ainda como correlativo metonímico da circularidade insular, táo cara à poética de Corsino, e que se completa no tríptico representado por cada uma das três palavras do título, culminando com a palavra Deus, fecho de um círculo perfeito e neoplatónico, cujo centro está em toda a parte. ${ }^{8}$ Seria ainda possível encontrar nessa cabeça

\footnotetext{
${ }^{8}$ É de lembrar a leitura que Christina Ramalho faz das implicaçôes ternárias do título e da estrutura do volume: "Relacionando cada componente do título da obra a um dos livros, teríamos 'cabeça' indicando ser Pão ê fonema a primeira representaçáo da identidade cabo-verdiana, tomada em sua força de individualidade, marcando um 'ser' que desponta e se oferece à visão e à consideração. Com 'calva', imprimindo adjetivação à cabeça, atribuir-se-ia a Árvore \& tambor a missāo de caracterizar a fundo essa identidade recém-inaugurada, ainda que à custa de rememorar a dor do nascimento. Ao mesmo tempo, o sentido de 'calva' abre-se à ideia de ausência, de silêncio, de pulsão pelo preenchimento do sentido, que se alcança na fusão dos elementos naturais ('árvore') e culturais ('tambor'). Já 'de Deus', expressão tomada como locução adjetiva, indicando 'divina', daria a Pedras de Sol \& Substância a missão de 'fazer florescer a cabeça calva de Deus' através da simultânea valorização da identidade remota da terra cabo-verdiana" (2015: 41-42).
} 
a figuração circular da ilha árida e sem vegetação e, por isso também, calva. Deus, cuja criação se faz contar por meio do flat lux da Escritura, surge-nos aqui como uma figura da implicação da transcendência nos desígnios do mundo, temporalizada e antropomorfizada no plano imanente, que a poesia corsiniana faz confluir num mesmo ponto.

De sublinhar me parece o modo como os três livros que compóem $A$ Cabeça calva de Deus investem na aposição do plano do mundo físico (nos motivos do pão, da árvore e da pedra) aos da subtileza do som (fonema, tambor, substância), procedendo à sua mútua implicação numa lógica que se estabelece, desde logo, nessa espécie de par mínimo essencial da poesia de Corsino: refiro-me a pão e a fonema, que tem sido lido como credo poético contra a fome e o silenciamento impostos sobre Cabo-Verde, à época, em 1974, no período pré-independência.' Apesar de não textualmente explícita em nenhum momento do livro, parece-me evidente a presença irrecusável de um subtexto bíblico nessa dicotomia literária, que assoma sintomaticamente em outros momentos do livro, no rasto de uma relação intertextual contraída desde logo no título do primeiro livro, Pão \& fonema.

Refiro-me especificamente ao versículo do evangelho que perenizou a fórmula bíblica da tentação de Cristo no deserto, no auge da fome e da sede: "nem só de pão vive o homem, mas de toda a palavra que procede da boca de Deus" (Mateus 4: 4). É ela que aqui nos permite recolocar a pertinência do título escolhido para a trilogia, na medida em que reconfirma uma forma de inscrição do livro no filão de uma leitura potencialmente religiosa que o texto, desde o seu início, não deixa de convocar. De salientar ainda é o percurso arquitextual que o versículo estabelece com o seu correspondente no Antigo Testamento através da correspondência citacional "está escrito", assim topicalizando a tessitura do literário na relação que o livro estabelece com as suas referências, ao passo que faz reverberar sobre si a feição tipológica que, desde a hermenêutica de Fílon, e da escola de Alexandria, preconizadora da universalidade do logos, se reconhece ao texto bíblico: o Antigo Testamento anuncia o Novo, o Novo completa o Antigo, numa relação de foro profético ou tipológico.

$\mathrm{O}$ anúncio de um novo testamento, na verdade um terceiro testamento, não deixa de ser objecto de figuração poemática em Corsino Fortes, como veremos. O rasto da referencialidade bíblica encontra-se disseminado ao longo de toda a obra, do primeiro ao último volume, o que não deverá surpreender-

\footnotetext{
${ }^{9}$ Veja-se, com Ana Mafalda Leite, a fecunda possibilidade de significação deste título: "Pão - é a resultante da combinação positiva entre chuva e milho, componentes essenciais que oferecem a solução ao tradicional condicionalismo da fome e da seca, e que implicam, na sua ausência, imigraçáo. Este elemento inicial regenerativo acresce-se do segundo - fonema - que pressupóe o acesso à voz, à palavra, à alfabetização, à cultura [...] Os dois símbolos em aliança [...] representam o alimento físico e o espiritual, păo para o corpo, fone para a mente" (2001: 293).
} 
nos, tendo em conta a sua particular forma de titulação: o texto está pontuado de versículos, tabernáculos, tábuas, desertos, sangue, oraçôes, catedrais, que pautam com referências do imaginário bíblico muita dessa poesia. É um tal imaginário que se insinua por meio de uma sacralidade difusa, atravessando o texto e fazendo do exercício da poesia um ofício que procura, por meio do rito poético, fundar uma nova aliança entre o Homem e Deus, a terra e o céu, o pão e o fonema - como é o caso nestes versos dirigidos a esse arquétipo do humano no paraíso da ilha:

Ouve-me primogénito da ilha [...] Aqui / Ergo a minha aliança / De pão e fonema / Enquanto / o vento bebe meu sangue a barlavento (2010:54)

Quando a ilha é sacerdote / E o mar é catedral / E o poente! Oração / que se ergue / Entre o mar E o seu cardume / O anzol aproxima-se do ofício / Como o céu da boca / Entre a hóstia e a comunhão (128)

Parece-me de destacar nesta passagem a recorrência da função apelativa da linguagem, reforçada pelo concurso do deíctico "aqui" e do marcador temporal "enquanto", contribuindo para a configuração oficiante do poema, que no fundo constitui um ritual de sacrifício do poeta (ali representado na figura de Cristo derramando o seu sangue em benefício desse primeiro homem, o primogénito da ilha, um Adão cabo-verdiano). Por essa via se sugere a instauração de uma nova aliança teológica (que a sinalética do título "pão \& fonema" não deixa de reforçar), estabelecida por meio da criação demiúrgica que só a poesia torna possível: a consagração do pão e do fonema à mesa de um novo pacto assinado com sangue, numa forma de "simbólica eucaristia", na formulação feliz de Ana Mafalda Leite (2001: 294).

Julgo ser de referir ainda o modo como esse imaginário religioso se manifesta através de referências explicitamente bíblicas, de que a não menor delas é a recorrência da palavra versículo, a par de designaçóes genológicas como as que encontramos nesta passagem: "[Poesia que é como] parábola do amor que dança / Entre o verbo e o apocalipse" (2010: 179). Ou ainda desta outra: "Por vezes é Domingo E sentamos / Na pedra da manhã plena / Então! Saudamos o tambor / E o versículo que chega / Ao fim do dia E nomeia / o seu povo E a sua lei / entre o fogo do Eclesiastes / E a parábola do Testamento de Amílcar" (113).

A conjugação binária de pão e fonema, qualquer que seja a leitura que façamos da copulativa "e", que na verdade tanto pode ser um elemento de ligação como de disjunção, vai aqui sendo vertida em outros pares antinómicos como os de tambor e versículo, povo e lei, Eclesiastes e parábola. No entanto, todos estes elementos requerem uma leitura circunstanciada, na medida em que a sua convocação textual ali excede a mera referencialidade bíblica; eles 
são na verdade duplamente referentes, ao permitirem endereçar também o horizonte do seu próprio tempo, a sua inscrição histórica: ali encontramos o tambor, destoando do leque de referências bíblicas e simultaneamente ressituando-as, assim trazendo diante do leitor o recorte cabo-verdiano de um outro povo (eleito) e de uma outra lei (mosaica); do Eclesiastes, livro sapiencial das Escrituras hebraicas, o fumo da vaidade (o havel que a Vulgata de Jerónimo traduziu por vanitas) transforma-se em fogo - não apenas o do elemento natural que habita as entranhas vulcânicas da terra, como também o que é produzido pela guerra dos homens, na defesa de um povo e de uma lei, lei essa que já não é a do antigo decálogo de Moisés mas a de um novíssimo Testamento, desta feita de Amílcar Cabral, líder do movimento anticolonial de libertaçáo e arauto de um tempo novo.

O poema, mesmo na sua dimensão mítica e ancestral, está assim implicado na corrente do tempo, infundindo no plano do kairós humano a expressão do kronos transcendente. Diz a voz poética, dirigindo-se a um dos seus múltiplos interlocutores, desta feita o próprio texto: "Poema! Que o tempo / Não peça milagres [...] Não me peças milagres / por favor / pedeme revolução! Camarada / Não \& somente a revolta da página sob o olho da terra [...] mas a revolta do páo / entre o sangue e a seiva / Mas revolta do rosto / entre a roda e o mundo" (2010: 93).

Palavras como revolta, roda e mundo, sugerem a figura do movimento, a da alteração da ordem, no sentido de uma revolução que não se atinge senão pela intervençáo do humano - repare-se como são os elementos do concreto (pão, sangue, seiva, rosto) que estão na origem da mudança e não a esperança numa solução tipificada pelo mecanismo do deus ex-machina (também nisso a poética de Corsino pertence mais ao âmbito da épica do que da tragediografia grega). As volutas da história não estão assim na dependência de um milagre transcendente, mas tâo-somente de um milagre humano: bem representativo disso é a transformação sofrida pela "cabeça calva" do título, que num dos momentos mais expressivos da obra vem a tornar-se a expressão do "silêncio de Deus / como um crânio de céu aberto" (2010: 113).

A visão pós-apocalíptica da morte de Deus pode ser aqui tomada como a última expressão possível da transcendência, que resgate afinal a temporalidade humana para um novo recomeço. Lê-se ainda, na seguinte passagem, o ímpeto da invenção do tempo apocalíptico que reinstala o tempo genesíaco pela reescrita do versículo do Eclesiastes, que aqui parece ser directamente endereçado: "Versículo! Muito há de novo / Debaixo da roda do sol" (2010: 165). "Tempo de ser ovo / ovo de ser tempo: Vem! Vem!" (166). Nestes versos, a fraseologia reconhecível do Eclesiastes, segundo o qual "não há nada de novo debaixo do sol" e "para tudo há um tempo", é objecto de uma configuraçáo correctiva que abre a história ao movimento da 
criação, o tempo do ovo (e, não por acaso, se discute de um ponto de vista exegético se a narrativa do Génesis trata ou não do início do mundo ab ovo), cuja figuração sugestiva associa o início à circularidade sinedóquica da ilha.

Repare-se ainda como a injunção de um novo tempo é marcada pelo desiderativo "Vem! Vem!": se, por um lado, ela acorda o eco da retórica epitalâmica do Cântico dos cânticos, da expressão desejante da presença do amado (que derivou entre nós na "cantiga de amigo"), por outro, ela não deixa de convocar um apelo verdadeiramente escatológico. Trata-se, de facto, daquilo a que Derrida chamou o "tom apocalíptico" (1983), o da invocação da persona do desejo, que retoricamente constitui a projecção da presença do elemento aguardado: é a articulação verbal dessa espera que presentifica o sujeito, o messianiza no anúncio da sua vinda (ou parusia), o momento afinal que encerra a Bíblia e vem desvelar o sentido da revelação. Lembro, a propósito, as palavras de fecho do Apocalipse: "Vem, vem, Senhor!" (22: 20).

São essas as sílabas sobre as quais assenta a escritura de um novo pacto, firmado sobre a pedra mineral de Cabo Verde, que na obra de Corsino surge figurada como "rocha scribida". ${ }^{10}$ Figuração da escrita mineral, esta é simultaneamente a pintura rupestre que atesta a presença ancestral da vida humana ali, mas também a nova tábua da lei que fundará um tempo novo, como se lê no poema "Golpe de Estado no paraíso": "Na História! Na Bíblia da nossa terra / Se a rocha é página, a pedra é sílaba” (2010: 188); “Ó bíblia de murmúrio / na tua semântica / De sal e paradoxo / Ó universo de mil sons / Que circulam / Pela maternidade / Do versículo que nos une / Na tua chama / Na tua lava / No teu tambor inenarrável” (196).

Esta passagem dá-nos a medida da dimensão verdadeiramente profética desse livro, cujo sentido profundo dimana da confluência de dois modelos literários distintos, o épico e o bíblico, que se interligam e polarizam numa tensão singular na poesia de Corsino Fortes. Ao invés de uma precedência do modelo épico sobre o profético, parece-me ter cabimento a colocação inversa das variáveis dessa equação literária: o profético que aqui vemos encenar-se não é o do maravilhoso mitológico que conduz o destino do herói humano, mas antes a afirmação de uma vontade telúrica e imanente (em certa medida oposta à do evasionismo terralongista da geração poética dos claridosos), politicamente organizada ao ritmo de um tambor versicular que hipostasia

\footnotetext{
${ }^{10} \mathrm{Na}$ leitura de Christina Ramalho, a "rocha" integra um "somatório de imagens míticas relacionadas ao tempo imemorial do surgimento da terra e, principalmente, da palavra cabo-verdiana, aqui entendida como real possibilidade de voz e expressâo. Apesar de Cabo Verde ter sido habitado a partir da chegada dos portugueses, imagens míticas como a da rotcha scribida (com traços rupestres que indicam uma presença ancestral nas ilhas) denunciam o desejo de transgredir o registro histórico em busca de um 'si-mesmo' pautado por outra lógica que não aquela que, convencionalmente, organiza o sentido da distribuição da presença humana nos continentes" (2012: 205-206). Veja-se ainda, sobre as imagens míticas nessa poesia, outro artigo (RAMALHO, 2014).
} 
a presença humana num paraíso confrontado com o ímpeto irresistível da história. Ao mito hesperitano da nostalgia de um paraíso perdido, de que falava Manuel Ferreira a propósito da literatura cabo-verdiana, Corsino opóe o senso adâmico de rebeliáo no seio do próprio paraíso, seguindo no rasto da lição bíblica. É perante a verbalização desse "paradoxo" poético que Corsino nos coloca, num gesto profundamente humano, mais mosaico que musaico ${ }^{11}$, solicitando uma outra linguagem crítica para ser compreendido no seu alcance mítico-simbólico profundo, o da relação da profecia bíblica com a história.

Destaco, a esse respeito, a leitura de William Franke em Poetry and Apocalipse (2009: 23), segundo a qual a profecia é essencialmente uma modalização discursiva de interpretação paradoxal da história, na medida em que a poesia profética propõe uma interpretação da história a partir da perspectiva da revelação da eternidade; o que implica a visão de uma finalidade, que está para além dos fins do tempo e em que reside a explicação totalizante, cósmica, de todos os acontecimentos singulares que pontuaram a história e a libertaram a cada momento para a feitura de si própria. Franke prossegue ainda apontando para a coincidência entre o discurso épico e o discurso profético, destacando a sua centralidade na tradição literária ocidental: "it is not primarily about predicting the future. It is rather about seeing deeply into the overall meaning of history and the cosmos so as to be able to convey their truth in a way that is total and as such tantamount to a type of divine revelation" (2016: 7).

Disto decorre a seguinte observação conclusiva: se a poesia de Corsino parece incorrer numa certa ilegibilidade semântica que afecta a sua percepção enquanto poema épico, estou convencido de que tal não ficará a dever-se apenas ao experimentalismo surrealizante e grafista da sua obra, à sua materialidade pictórica de efeitos disruptivos na condução da leitura. Esse efeito decorrerá ainda do facto de essa poesia incorporar a leitura convulsiva da história e de assumir-se como proposta sobre o que pode ser a actualizaçáo literária de um discurso poético sobre a história. É próprio da tradição da poesia profética quebrar, afinal, as regras do jogo da linguagem, a fim de articular aquilo que não pode ser dito dentro do sistema de convençôes gramaticais e lexicais dessa mesma linguagem. A poesia pode apenas acenar com a promessa (ou vinda) de um sentido que permanece por revelar e é, nessa medida, em si

\footnotetext{
${ }^{11}$ A inscrição da palavra na rocha mimetiza o gesto de Moisés da escrita do decálogo nas tábuas da lei, preterindo, assim, o modelo épico da inspiração por recurso às musas como figura mitopoética da inspiraçáo, como encontramos no diálogo platónico referido na abertura deste ensaio. Veja-se ainda a reflexão de Maurice Blanchot sobre a dimensão profética nas culturas grega e bíblica: "Entre os gregos [...] o ser em transe que atinge na loucura a adivinhação inspirada revela, por um balbucio que nem sequer é uma palavra, o segredo que os profetas, padres ou poetas, poetas-padres, se encarregaráo de interpretar, quer dizer de elevar à linguagem humana. No mundo bíblico, diz Max Weber, a pítia e o intérprete não estão separados: o poeta de Israel reúne ambos num só ser. É que a adivinhaçáo grega ainda náo é linguagem [...] No mundo bíblico, aquele a quem o espírito toca fala uma palavra já em verdadeiro começo” (1984: 87).
} 
mesmo irrepresentável. Apenas a poesia, na sua conformação de linguagem em processo de refeitura poiética, no sentido que etimologicamente lhe assiste, seria adequada à representação desse irrepresentável, pois que este enquanto tal está aquém da possibilidade de re-presentação.

A estética profetizante da literatura apocalíptica descreve afinal o movimento de oscilação entre o momento da formulação verbal e o da dissolução dessa mesma forma, coincidindo com o gesto de reinvenção da representação. Creio que é perante um fenómeno dessa natureza que nos avizinhamos quando lemos Corsino Fortes. Se $A$ Cabeça calva de Deus pode dizer-se um poema épico, então não poderá deixar de ser também uma epopeia de versículos, essa unidade mínima do texto bíblico em que se actualiza o fonema corsiniano, ou um novíssimo testamento feito de cantos. A modulação teopoética que da história ali se propóe não é menos compaginável com a dimensão da profecia bíblica do que com a de um projecto épico de refundação do mundo, que o projecto apocalíptico não deixa de conter (e afinal em função do qual se define). Nessa trilogia, Corsino não faz apenas a leitura do seu horizonte histórico, político e simbólico, ele procura fazêlo num diálogo compósito e heteróclito que, na verdade, encena um "acto cultural”, na linha de pensamento de Amílcar Cabral. Trata-se, assim, de uma poesia que, a seu modo, historiciza o mito sem deixar de remitologizar a história - a Bíblia não fala de outra coisa senão disto mesmo.

\section{Referências bibliográficas}

ALVES, Hélio. 2010. Epopeia. E-dicionário de termos literários. Coordenação de Carlos Ceia. Disponível em <http://edtl.fcsh.unl.pt/business-directory/6048/epopeia/ >

AUERBACH, Eric. [1946]. Mimesis. The Representation of Reality in Western Literature. Princeton: Princeton University Press, 2003.

BLANCHOT, Maurice. [1959]. O Livro por vir. Lisboa: Relógio d'Água, 1984.

CUERVO, Elena Maria. Juvenco y la épica bíblica: especificidad y crítica literaria. Teoliteraria 1, v. 1, 2011, p. 14-28.

CURTIUS, Ernst. [1952]. European Literature and the Latin Middle Ages. Princeton: Princeton University Press, 1990.

DERRIDA, Jacques. De um tom apocalíptico adoptado há pouco em filosofia. Lisboa: Vega, 1983.

FORTES, Corsino. A Cabeça calva de Deus. São Paulo: Escrituras, 2010. 
FRANKE, William. Poetry, Prophecy and Theological Revelation. Oxford Research Encyclopedia of Religion, May 2016, p. 1-28.

. Poetry and Apocalipse. Theological Disclosures of Poetic Language. Stanford: Stanford University Press, 2009.

FRYE, Northrop. [1957]. Anatomy of Criticism. Four Essays. Princeton: Princeton University Press, 2000.

LARANJEIRA, Pires. Literaturas africanas de expressão portuguesa. Lisboa: Universidade Aberta, 1995.

LEITE, Ana Mafalda. A Cabeça calva de Deus. Uma trilogia épica fundacional. In: A Cabeça calva de Deus. Lisboa: Publicaçóes Dom Quixote, 2001. . Modalização épica nas literaturas africanas. Lisboa: Vega, 1996.

RAMALHO, Christina. A Fala autoral e o plano literário de A Cabeça calva de Deus. In Literatura cabo-verdiana. Leituras universitárias. Edição de Gomes, Mantovani e Pereira. Cáceres: Unemat, 2015, p. 31-46.

. As Imagens míticas cabo-verdianas em A Cabeça calva de Deus, de Corsino Fortes. Revista Barbante, n. 12, 2014, p. 79-97. . Sobre a invocação épica. Cadernos de Letras da UFF, n. 47, 2013, p. 373-391. - A Cabeça calva de Deus, de Corsino Fortes: uma trilogia épica carbo-verdiana e universal. Via atlântica, n. 22, 2012, p. 203-206.

RUBINSTEIN, Ernest. Religion and the Muse. The Vexed relation between Religion and Western Literature. New York: State University of New York Press, 2007.

Gonçalo Cordeiro. Professor na Universidade de Macau. Doutor em Literatura Comparada pela Universidade de Lisboa, com uma tese distinguida pelo Centro de Literatura Portuguesa da Universidade de Coimbra. Ensinou em Estrasburgo (França) e em Díli (Timor-Leste). Integra a equipa de investigação do Centro de Estudos Comparatistas da Universidade de Lisboa. A sua investigação privilegia os estudos de mitocrítica e religião, bem como as literaturas em língua portuguesa. E-mail: g_cordeiro@sapo.pt

Recebido em: 15/01/2017

Aprovado em: 15/03/2017 